\title{
Violência sexual: caracterização e análise de casos revelados na escola
}

\author{
Sexual violence: description and analysis of cases \\ detected in the school environment
}

\author{
Silvia Regina VIODRES INOUE ${ }^{1}$ \\ Marilena RISTUM ${ }^{2}$
}

\begin{abstract}
Resumo
Estudos sobre violência sexual contra crianças e adolescentes indicam que familiares e conhecidos são os maiores agressores, tornando dif́́cil a sua denúncia. Na infância e na adolescência, a escola pode ser um local ideal para detecção, intervenção e promoção de fatores de proteção que diminuam a violência e seu impacto sobre o desenvolvimento. Este trabalho teve como objetivo analisar os casos de violência sexual identificados ou revelados no contexto educacional, descrevendo suas formas, incidências, perfil da vítima, do agressor, do responsável pela identificação e circunstância da revelação. As ocorrências foram selecionadas dentre os 2522 protocolos de atendimento de um programa estadual de denúncia e assistência a vítimas de violência sexual, e totalizaram apenas 22 casos. Nestes, houve o predomínio do sexo feminino e idade até 12 anos. A professora foi a maior responsável pelo desvendamento, que ocorreu principalmente por meio de relatos verbais das vítimas.
\end{abstract}

Unitermos: Abuso de criança. Escolas. Identificação da violência. Violência sexual.

\begin{abstract}
Studies on sexual violencetowardschildren and teenagers havedemonstrated that familymembersand acquaintancesarethemost usual aggressors, which makes it all the more difficult to makeaccusations. During childhood and adolescence, the school setting might bethe ideal place for detection, intervention, and promotion of features of protection to reduce violenceand its impact upon their development. The aim of this paper was to analyze cases of sexual violence identified or revealed in educational settings, describing its forms, incidence, victim and aggressor profiles, as well astheindividuals responsiblefor their identification. Twenty-two cases havebeen selected out of 2522 records provided bya stateaccusation program that offers support to victims of sexual violence. The data also show that victimsaremainly females under the age of 12 . Teachers were largely responsible for revealing the cases, which were mainly verbally communicated by the victims.

Uniterms: Child abuse. Schools. Identifying violence. Sexual abuse.

A violência, hoje considerada uma das principais causas de morbimortalidade, especialmente na população jovem, atinge crianças, adolescentes,

homens e mulheres, de diferentes etnias, classes sociais, culturas ou religião (Ministério da Saúde, 1998). Nas estatísticas da violência praticada na sociedade brasileira

\footnotetext{
${ }^{1}$ Universidade Federal da Bahia, Faculdade de Filosofia e Ciências Humanas. Estrada de São Lázaro, 197, 40210-730, Federação, BA, Brasil. Correspondência para/Correspondence to:S.R. VIODRES INOUE. E-mail:<viodres@ufba.br>.

2 Universidade Federal da Bahia, Faculdade de Filosofia e Ciências Humanas, Programa de Pós-Graduação de Psicologia. Federação, BA, Brasil.

Apoio: Conselho Nacional de Desenvolvimento Científico e Tecnologia.
} 
destaca-se, com grandes proporções, a violência contra crianças e adolescentes, em que a família aparece como a maior violadora dos direitos infanto-juvenis (Pereira da Silva, 2000).

A partir da década de 1960, nos Estados Unidos, a questão da violência contra crianças e adolescentes emergiu como um problema médico-social. A repulsa social advinda da área médica em relação à violência sexual tomou impulso, ao lado do avanço do movimento feminista, ainda nos Estados Unidos, na década de 1970. 0 reconhecimento da morbimortalidade em decorrência da violência como um grave problema para a saúde fez com que surgissem os movimentos de prevenção e atenção especializada, na década de 1980 (Minayo, 2002).

No Brasil, nesta mesma década, de acordo com Minayo (2002), surgiram os primeiros diagnósticos de maus tratos e propostas de intervenção que, posteriormente, contribuíram para o desenvolvimento do Estatuto da Criançae do Adolescente (ECA), promulgado em julho de 1990, pela Lei Federal n. 8.069/90. Este estatuto garante à população infanto-juvenil, segundo Pereira da Silva (2000), o respeito enquanto pessoas em condição peculiar de desenvolvimento. Entretanto, deve-se considerar que, entre o preceito legal do ECA e a prática dos diversos profissionais que se deparam com as evidências dos maus tratos, há ain da uma distância a ser vencida, uma vez que nem sempre os profissionais se sentem preparados para assumir tais atribuições (Gomes, Junqueira, Oliveira Silva \& Junger, 2002).

Na literatura, a violência é conceituada de diferentes formas, não havendo critério quanto às rotulações e classificações, ou, quando se utilizam critérios, estes são confusos, dificultando seu uso por outros pesquisadores (Ristum \& Bastos, 2004). Embora a definição de abuso sexual pareça óbvia, trata-se de um tema bastante controverso, envolvendo questões relativas à normalização da sexualidade humana. Para dimensionar o fenômeno com maior precisão, compreendê-lo e preveni-lo, é necessário verificar sua prevalência e incidência. Um problema inicial, apontado por Kristensen, Flores e Gomes (2001), e Polanczyk, Zavaschi, Benetti,Zenker e Gammerman (2003), é que os dados relativos à prevalência de abuso sexual apresentam grande variabilidade de acordo com a definição utilizada, de modo que uma conceituação limitada tende a
Apesar das dificuldades conceituais, várias são as definições encontradas na literatura, como a proposta por Kristensen et al. (2001), que definem o abuso sexual de crianças e adolescentes enfatizando as limitações do seu estágio de desenvolvimento, as expectativas sociais dos papéisfamiliares e as relações de poder entre agressor e vítima.

A literatura apresenta uma imprecisão terminológica (Knutson, 1995), em que a utilização de diferentes palavras como sinônimos ou como correspondentes a um mesmo conceito revela a falta de uma rigorosa e clara conceituação (Faleiros \& Campos, 2000). Todos os termos utilizados para conceituar as diferentes modalidades de crimes sexuais apresentam dificuldade em atender adequadamente aos aspectos médico, jurídico, psicológico e ético que tais crimes envolvem (Drezett, 2004).

Já a inclusão do abuso sexual na categoria de maus tratos deve-se ao fato de que, segundo Faleiros e Campos (2000), os primeiros estudos sobre violência contra crianças e adolescentes foram realizados a partir do atendimento a vítimas de maus tratos físicos. Essas mesmas autoras colocam que o abuso sexual deve ser entendido como:

... uma situação de ultrapassagem de limites, de direitos humanos, legais, de poder, de papéis, do nível de desenvolvimento da vítima, do que esta sabe e compreende, do que o abusado pode consentir, fazer e viver, de regras sociais e familiares e de tabus. E que as situações de abuso infringem maus tratos às vítimas (Faleiros \& Campos, 2000, p. 7).

Por outro lado, de acordo com o Ministério da Saúde (2002), o uso difundido da expressão "maus tratos" é impreciso e inadequado, uma vez que conduz à suposição de que os "maus tratos" se oporiam aos "bons tratos". Estaria implícita, então, uma conotação apenas moral, enquanto que a violência contra esta população é um grave problema social, subjacente aos valores culturais de que esses seres em formação seriam propriedade de seus pais e que, para educá-los, seria preciso puni-los quando erram ou se insubordinam. De acordo com a definição do Ministério da Saúde (2002), 0 abuso sexual consiste em:

... todo ato ou jogo sexual, relação heterossexual ou homossexual cujo agressor está em estágio de desenvolvimento psicossexual mais adiantado que a 
criança ou adolescente. Tem por intenção estimulá-la sexualmente ou utilizá-la para obter satisfação sexual. Apresenta-se sob a forma de práticas eróticas e sexuais impostas à criança e ao adolescente pela violência física, ameaças ou indução de sua vontade. Esse fenômeno violento pode variar desde atos em que não se produz o contato sexual (voyerismo, exibicionismo, produção de fotos), até diferentes tipos de ações que incluem contato sexual sem ou com penetração. Engloba ainda a situação de exploração sexual visando lucros como é o caso da prostituição e da pornografia (Ministério da Saúde, 2002, p.13)

Faleiros e Campos (2000, p.10) finalizam sua discussão sobre os conceitos de violência sexual, abuso sexual e maus tratoscom a afirmação de que “... é possível compreender que estes três conceitos não são sinônimos e são epistemologicamente distintos". As autoras defendem que "violência" é a categoria explicativa da vitimização sexual, que se refere ao processo e à natureza da relação de poder estabelecida no abuso sexual. Já o abuso seria a situação de uso excessivo; de ultrapassagem de limites dos direitos humanos e legais; de abuso do poder; de uma deturpação dos papéis e regras sociais e familiares; de quebra de tabus, em que o adulto aproveita-se do nível de desenvolvimento da vítima, que ainda é incapaz de compreender a situação e, portanto, de dar ou não o seu consentimento. Maus tratos seria a descrição empírica do abuso sexual, referindo-se ao que é praticado pelo agressor e sofrido pela vítima, ou seja, os atos e conseqüências do abuso.

Segundo Gabel (1997), abuso, etimologicamente, indica inadequação do uso normal, mau uso, uso excessivo, ultrapassagem de limites e transgressão. A análise terminológica tem originado críticas quanto ao uso da expressão "abuso sexual", advinda da tradução do inglês sexual abuse, em que estaria implícito um uso sexual permitido de crianças e adolescentes por adultos. Assim, o abuso seria o uso sexual de crianças e adolescentes além do permitido.

Com base nas argumentações utilizadas na discussão sobre essa confusão conceitual, e especialmente nas colocações de Gabel (1997) sobre a expressão "abuso sexual", optou-se por adotar, neste trabalho, a expressão "violência sexual", por julgá-la mais adequada para abranger as dimensões da vitimização sexual.
Como todas as categorias de violência contra crianças e adolescentes, a violência sexual pode ainda comportar as sub-categorias: doméstica, intra-familiar e extra-familiar. A violência doméstica é exercida na esfera privada, dentro da residência da vítima; os agressores não são necessariamente familiares, podem ser outras pessoas que vivem na mesma casa. A violência sexual intra-familiar acontece dentro da família, é perpetrada por agressor que possui uma relação de parentesco ou vínculo familiar com a vítima e algum poder sobre ela, tanto do ponto de vista hierárquico (pai, mãe, padrasto e tios) como do ponto de vista afetivo (primose irmãos), e que vive ou não sob o mesmo teto da vítima (Araújo, 2002). As sub-categorias doméstica e intra-familiar não são necessariamente excludentes. $A$ violência praticada, por exemplo, por um avô contra seu neto, pode ser classificada como violência doméstica intra-familiar, por habitarem em um mesmo espaço físico e por possuírem laços familiares. Já a violência sexual extra-familiar ocorre fora do âmbito familiar, podendo ser cometida por conhecidos, como vizinhos e colegas, ou por desconhecidos. Quando a violência sexual é praticada por adolescentes, mesmo as vítimas sendo crianças, há uma tendência a considerá-la apenas como curiosidade juvenil ou experimentação sexual. Mas, segundo Amazarray e Koller (1998) e Drezett (2004), o que caracteriza a relação violenta e abusiva não é a diferença de idade, mas o uso de poder, autoridade ou força empregada pelo agressor.

\section{Os desafios da notificação}

Os estudos sobre o tema indicam que a maior parte da violência sexual contra crianças e adolescentes é praticada por parentes ou pessoas próximas e conhecidas, tornando maior a dificuldade da denúncia (Wolak \& Finkelhor, 1998). Estima-se que menos de 10\% dos casos cheguem às delegacias (Ministério da Saúde, 1998). Dentre os tipos de violência cometidos contra o ser humano, a violência sexual, segundo Williams (2002), é o delito menos denunciado na sociedade brasileira, por várias razões: o fato de a sexualidade humana ser ainda hoje tabu; sentimentos de culpa, vergonha e estigma, favorecedores de isolamento social; e o medo de represálias e ameaça. Em alguns casos, quando 0 agressor é um membro da família, o temor de que ele 
seja afastado se denunciado é um grande obstáculo à denúncia, pois o afastamento poderia resultar em implicações de ordem emocional e econômica.

Para Drezett (2000), a atitude da vítima em não denunciar a violência parece estar relacionada a múltiplos fatores, como constrangimento, medo de humilhação, de incompreensão de parceiros, familiares, amigos, vizinhos e autoridades, que muitas vezes culpam a vítima, acreditando, erroneamente, que a mesma possa ter favorecido ou provocado a ocorrência da violência, pelo uso de determinadas vestimentas, por atitudes, local e horário em que se encontrava na ocasião. No entanto, um estudo de Drezett (2000), entre outros, sugere que, na maioria dos casos, a vítima pouco contribuiu para aumentar o risco de contato com o agressor. Verificou-se que a maioria das vítimas encontrava-se no exercício de atividades habituais, próximas de suas residências, no percurso do trabalho ou da escola.

Mesmo variadas e imprecisas, as poucas estatísticas sobre 0 abuso sexual são assustadoras. Apesar das sub-notificações e de todos os obstáculos às denúncias, segundo estimativas do Fundo das Nações Unidas para Infância (Unicef), a cada ano, cerca de um milhão de crianças em todo o mundo são vitimizadas sexualmente (Agência de Notícias dos Direitos da Infância - ANDI, 2003). Os crimes sexuais adquiriram, de acordo com Drezett (2000), proporções de um complexo problema de saúde pública, considerando-se sua elevada incidência e prevalência, suas conseqüências biológicas, psicológicas e sociais, mesmo sen do sub-notificados.

O impacto da violência sexual no desenvolvimento emocional e acadêmico

A vítima de violência sexual está exposta a diferentes riscos, que comprometem sua saúde física e mental (Neves, Ramirez \&Brum, 2004). Asconseqüências da violência sexual são múltiplas, e seus efeitos físicose psicológicos podem ser devastadores e duradouros (Kaplan \& Sadock, 1990).

A literatura refere-se a alterações resultantes do impacto da vitimização sexual que seriam úteis para a sua identificação. Depressão, sentimentos de culpa, comportamento autodestrutivo, ansiedade, isolamento, estigmatização, baixa auto-estima, tendência à revitimização e abuso de substâncias, queixas somáticas, agressão, problemas escolares, transtorno de estresse pós-traumático (TEPT), comportamentos regressivos (enurese, encoprese, birras, choros), fuga de casa e ideação suicida são sintomas que podem aparecer na infância e se estender pela vida adulta (Boney-McCoy \& Finkelhor, 1995; Finkelhor\&Tackett, 1997; Williams, 2002).

As manifestações do TEPT na infância e adolescência são mais graves e comprometedoras, uma vez que as funções afetivas e cognitivas do sistema nervoso central não amadureceram e não foram ainda totalmente reguladas. Doenças sexualmente transmissíveis, traumas físicos e ginecológicos, gravidez, transtornos mentais e dificuldades no ajustamento sexual adulto são apenas algumas das possíveis conseqüências físicas, emocionais, sexuais e sociais da violência (Amazarray \& Koller, 1998).

Dentre os indicadores mais relatados, encontra-se o comportamento sexualizado, que não é exclusivo de crianças vítimas de abuso sexual, mas é considerado como o que melhor as identifica (Williams, 2004). As brincadeiras sexualizadas com bonecos, a introdução de objetos no ânus ou na vagina, em si mesmo ou em outras crianças, a masturbação excessiva em público, 0 comportamento sedutor, a solicitação de estimulação sexual e um conhecimento sobre sexo inapropriado à idade incluem-se nos comportamentos sexualizados.

É consenso, entre muitos pesquisadores, que há um severo impacto da vitimização por violência sexual no desempenho e na vida acadêmica da vítima. Alterações no desenvolvimento cognitivo, na linguagem, na memória e no rendimento escolar, rebaixamento da percepção do próprio desempenho e capacidade, agressividade e impulsividade têm sido freqüentemente relatados (Amazarray \& Koller, 1998; Ferrari \& Vecina, 2002; Finkelhor \& Tackett, 1997; Kaplan \&Sadock, 1990; Williams, 2002). No entanto, dados encontrados sugerem que as vítimas parecem ser afetadas de diferentes maneiras e graus; enquanto algumas parecem sofrer conseqüências mínimas, outras sofrem graves problemas sociais e psiquiátricos (Dattilio \& Freeman, 1995), portanto, não se deve esperar um perfil extremamente característico, pois isto limitaria o diagnóstico.

0 relacionamento entre agressor e vítima tem sido descrito como um dos fatores mais relevantes no 
agravamento do impacto da violência sexual. Outros fatores referentes à ação sexual em si, como a intensidade da violência sexual e não sexual, a força empregada, 0 número de agressores, assim como a freqüência e a duração da violência, também são apontados como agravantes que acentuam os danos e pioram o prognóstico (Williams, 2002). Ausência de figuras parentais protetoras, de apoio social, ou a resposta negativa da família/pares/educadores à descoberta da violência acentuam o dano (Amazarray \& Koller, 1998; Williams, 2002).

A escola como atenuante ou agravante de danos da violência sexual

Um fator importante no enfrentamento de um problema como a violência sexual é, segundo Lisboa et al. (2002), o fato de ele ser identificado em casa ou na escola, devido aos diferentes tipos de relações interpessoais, nas quais coexistem questões de hierarquia e poder. Outro fator que influencia o processo de identificação e enfrentamento é a própria violência doméstica. Crianças que são testemunhas ou vítimas de violência no ambiente doméstico tendem a desenvolver um repertório de estratégias inadequado, deficiente: aprendem estratégias agressivas para lidar com possíveis contrariedades e formam, assim, seu repertório de respostas ao estresse e às contrariedades. Agindo deste modo, são rejeitadas ou hostilizadas por colegas e professores; esta rejeição e hostilidade geram maior estresse, afetam o processo de aprendizagem e de estabelecimento de relações sociais e diminuem a probabilidade de revelação da violência sofrida, estabelecendo-se um círculo vicioso (Lisboa et al., 2002). Assim, o fracasso escolar e os comportamentos agressivos podem ter, em sua origem, a violência sexual.

Lisboa et al. (2002) colocam que as crianças vítimas de violência deveriam encontrar, na escola, fatores de proteção que diminuíssem tanto a violência quanto o impacto dela sobre seu desenvolvimento, e que favorecessem a implementação de estratégias de coping mais saudáveis e adaptativas. 0 microssistema escolar deve representar, para as crianças, uma alternativa de apoio, proteção e prevenção (Beland, 1996), principalmente para aquelas que não a encontram em sua família. As autoras chegam à lamentável conclusão de que as professoras, provavelmente, não possam ser consideradas fatores de proteção responsáveis pelas estratégias adaptativas das crianças vítimas de violência doméstica, e levantam a hipótese de que, mesmo as crianças que não são vítimas de violência doméstica, na escola se deparam com outros tipos de riscos que acarretam prejuízos ao seu desenvolvimento (Lisboa et al., 2002).

0 enfrentamento da violência exige a efetiva integração de diferentes setores como saúde, segurança, justiça e educação, bem como o envolvimento da sociedade civil organizada. Infelizmente, não se tem uma atuação da educação preconizando a prevenção e a intervenção. Além do cuidador (familiar ou responsável), o educador talvez seja quem mais tempo permaneça com a criança e 0 adolescente, considerando a carga horária do sistema de educação brasileiro, e talvez perca, com a atual postura adotada, a única oportunidade de reconhecimento e intervenção, nos casos de violência contra esta população. Brino e Williams (2003) concordam que a escola seria um lugar ideal para detecção e intervenção nos casos de abuso sexual infantil, uma vez que 0 agressor contra esta população freqüentemente se encontra na família.

A escola deve se comprometer com a garantia dos direitos das crianças e dos adolescentes, e a adesão dos educadores fortalece a militância em defesa desses direitos. A atuação do professor na identificação e denúncia da violência sexual é fundamental, principalmente nas primeiras séries, quando os educadores permanecem cerca de quatro horas diárias com as crianças.

É preciso entender que a educação é um processo de construção coletiva, contínua e permanente de formação do indivíduo, e a escola é o local privilegiado dessa formação, porque trabalha com 0 conhecimento, com valores, atitudes e formação de hábitos (Monteiro Silva, 1995). Para tanto, a escola deve restabelecer seu papel de agenciadora do saber e do conhecimento; abandonar a postura op ressiva, na qual se confundem disciplina e autoritarismo; e adotar uma disciplina transformadora, consciente e responsável (David, 1997). Para Faleiros (1998), "a família e a escola são redes fundamentais de articulação desse processo de formação da identidade, de proteção, de socialização da criança" (Faleiros, 1998, p.5). 
A literatura apresenta poucos dados a respeito do papel da escola diante da violência e de sua contribuição como espaço de proteção, socialização e formação infanto-juvenil e, especificadamente, na identificação e notificação da violência sexual. Assim, objetivou-se analisar, dentre os casos de violência sexual atendidos pelo Serviço de Atenção a Pessoas em Situação de Violência Sexual (Viver), aqueles que foram identificados ou revelados no universo educacional, caracterizando suas formas e incidências, o perfil da vítima, do agressor e do responsável pela identificação, bem como a natureza do vínculo entre eles, os tipos de crime perpetrados e os indicadores percebidos, e as formas de constrangimento ou coerção utilizadas pelos agressores.

\section{Método}

Para a coleta de dados, foram utilizados os registros das informações prestadas pela vítima e/ou por seu representante legal, contidas no Protocolo de Atendimento de Usuários do Viver, de Salvador, Bahia. No período de 21 de dezembro de 2001 a 31 de agosto de 2004 (ou seja, desde o início do projeto até a data da coleta de dados), somaram-se 2522 protocolos de atendimento. Constituíram o material de estudo e análise, dentre os 2522 protocolos, todos os que se referiam à violência sexual identificada ou revelada no contexto educacional, perfazendo um total de 23 protocolos que, no final, reduziram-se a 22, porque um deles estava com dados insuficientes e foi excluído.

\section{Procedimentos}

Após a leitura integral dos 2522 protocolos, foram selecionados os que se referiam à revelação ou descoberta da violência dentro do espaço escolar. Os dados foram transcritos em formulário específico, construído de forma a contemplar os objetivos da pesquisa. Foram excluídos protocolos com dados insuficientes, ilegíveis ou confusos.

\section{Resultados e Discussão}

Inicialmente, foram verificados 23 casos de violência sexual, identificados ou revelados na escola.
Destes, um protocolo com dadosinsuficientesfoi excluído, de modo que foram analisados 22 protocolos. Os 23 casos constituíram 0,91\% do universo de 2522 casos. Esse primeiro dado é um forte indicador da pouca participação da escola na identificação da violência sexual sofrida por seus alunos, considerando que, do total de $2522,73,00 \%$ tinham até 18 anos, fazendo supor, portanto, uma alta incidência de escolares.

Para facilitar comparações com outros trabalhos, as faixas etárias utilizadas para classificar as vítimas foram estabelecidas de acordo com o ECA (Conselho Estadual dos Direitos da Criança e do Adolescente, 1990), que coloca a infância na faixa "até 12 anos" incompletos, a ad olescência na faixa de "12 a 18 anos" incompletose a classificação "acima de 18 anos" para se referir à idade adulta. A idade de maior incidência foi a de cinco anos, com percentual de $27,72 \%$, seguida pela de nove anos, com $18,18 \%$.

Entre os 22 casos analisados, evidenciou-se 0 predomínio do sexo feminino, com $86,36 \%$ dos casos, e idade "até 12 anos", com 77,27\% dos casos. Embora a violência sexual possa ocorrer em qualquer idade, há uma predominância entre mulheres mais jovens e adolescentes, o que se confirma na presente pesquisa (Drezett, 2000). As escolaridades de maior freqüência foram "creche" e "1a a 4a séries", ambas com 40,90\%. Dos 22 casos analisados, 18 se referiam a vítimas que cursavam séries inferiores à 5 a e que, provavelmente, permaneciam grande parte do turno escolar com um único professor, o que pode ter facilitado tanto 0 desenvolvimento de um vínculo de confiança, quanto favorecido a observação de alterações no comportamento do aluno. 0 único caso em que a vítima tinha 18 anos foi o de uma garota com deficiência mental. Em qualquer idade, a condição de deficiência mental constitui importante fator de vulnerabilidade, sendo que há estimativas de que $50 \%$ das deficientes mentais são sexualmente abusadas ao menos uma vez em suas vidas (Drezett, 2000).

A distribuição por sexo, dos 2522 protocolos, mostra $200(7,9 \%)$ casos de vítimas de sexo masculino, com uma grande concentração na faixa etária "até 12 anos" (185 casos); destes, apenas três foram identificados pela escola, apesar de os 185 meninos estarem todos na faixa etária de escolanização fundamental. Há evidências de que o problema da sub-notificação seja maior

2008 
quando as vítimas são do sexo masculino (Drezett, 2000). Dentre as razões possíveis, há a subestimação do impacto da violência sexual no garoto, temor pela exposição e questionamento de papel e orientação sexuais, além da maior dificuldade de o homem relatar a violência.

Faz se necessário lembrar que o primeiro ambiente de vivência e socialização da criança é o familiar, e a escola, o segundo. Quando a família é a perpetradora da violência contra a criança e 0 adolescente, ou quando ela fracassa em seu papel de provedora, formadora e protetora, a escola será, em muitos casos, a única a zelar pela proteção dos educandos, uma vez que a família torna-se omissa, agressora ou transgressora de sua função. Não se trata de a escola trazer para si a responsabilidade que é da família, mas sim, contribuir para que esta possa conhecer sua função e responsabilizar-se, tendo como alternativa para isto, por exemplo, o ensino do exercício de cidadania, o esclarecimento, as orientações aos familiares e, quando cabível, a denúncia das agressões para os órgãos competentes.

De 2522 casos de violência atendidos pelo Viver, durante 32 meses, apenas 22 foram identificados pelos educadores e obtiveram um encaminhamento, ou seja, após a denúncia receberam atendimento médico, jurídico, social e psicológico. Estes dados, de fato, alertam para um grave problema: ou os educadores não conhecem os direitos de sua clientela, ou são igualmente violadores destes direitos, quando, apesar de conhecê-los, omitem-se frente a suspeitas ou confirmações de violência sexual, não a denunciando. Cita-se aqui 0 artigo 13으 ECA (Conselho Estadual dos Direitos da Criança e do Adolescente, 1990), no qual, diante de suspeita ou confirmação de que crianças ou adolescentes sejam vítimas de violência sexual, deve-se obrigatoriamente denunciar o caso ao Conselho Tutelar ou ao Ministério Público, ou ainda, a Delegacias especializadas.

Quanto à identidade do perpetrador, praticamente todos os agressores (25) eram conhecidos da vítima, havendo apenas um caso de agressor não identificado. Esses dados corroboram os da literatura, que mostram a prevalência do agressor conhecido nos casos de violência contra crianças menores de 12 anos. 0 perpetrador desconhecido assume uma freqüência maiorapósa adolescência, dada a incidência de estupros e crimesque ocorrem freqüentemente em vias públicas. Apesar da perplexidade causada por tal constatação, é incontestável que a agressão sexual durante a infância é cometida por pessoas que a criança conhece e em quem confia (Drezett, 2000), favorecendo a não revelação e o prolongamento do processo até a idade adulta.

Quanto ao vínculo existente entre agressor e vítima, verificou-se uma maior freqüência de violência intra-familiar $(56,0 \%)$. A segunda categoria de maior freqüência, "pessoa conhecida" $(40,0 \%)$ refere-se a agressores conhecidos, mas sem qualquer parentesco com a vítima como, por exemplo, comerciante, conhecido da rua ou vizinho. De acordo com dados da Associação Brasileira Multiprofissional de Proteção à Infância e à Adolescência (ABRAPIA) (1997), no contexto das violências sexuais, o pai biológico é 0 agressor mais freqüente. Concordando com esses dados, Azevedo e Guerra (1988) relatam pesquisa em que o pai biológico foi o maior responsável em cerca de $30,0 \%$ dos casos e, em seguida, o padrasto, responsável por $12,00 \%$. No estudo a que se refere este artigo, dentre os familiares agressores, verificou-se que o padrasto (cinco casos, ou $35,7 \%$ ) e o pai biológico (quatro casos, ou $28,6 \%$ ) são os principais agressores. Considerando o tempo decorrido entre a pesquisa de Azevedo e Guerra (1988) e esta, pode-se supor que as mudanças nas configurações familiares, com um maior número de uniões conjugais desfeitas, tenha aumentado o número de padrastos em contato com os filhos de suas parceiras.

Os agressores, todos do sexo masculino, somavam um total de 25 , pois em dois casos houve mais de um agressor. Foram analisadas as idades de 22 dos 25 agressores, já que, em três casos, as vítimas ou seus responsáveis não souberam estimar as idades. Houve o predomínio de idades "acima de 40" anos (36,36\%), seguidas por idades "de 31 a 40 anos" (22,72\%) e "até 20 anos" $(22,72 \%)$, com uma variação de 15 a 54 anos. Nos resultados encontrados por Azevedo e Guerra (1988), ocorreu o predomínio da faixa etária do agressor de 30-39, seguida pela de 40-49 anos. A literatura a respeito dos agressores sexuais é escassa, havendo um maior interesse no estudo de questões relativas às vítimas. Outras características como escolaridade, raça, ocupação e estrutura familiar dos agressores não foram analisadas, pois os prontuários não dispunham de tais informações. 
Em relação à forma de violência sexual mais praticada contra crianças e adolescentes, os dados encontrados foram compatíveis com a literatura. Verificou-se uma alta incidência de atos libidinosos (59,09\%) na faixa etária "até 12 anos", em uma proporção bem maior que de atos considerados relação sexual (18,18\%), ou seja, aqueles envolvendo sexo oral e relações sexuais vaginal e anal. É provável que a preferência do agressor pelos atos libidinosos se justifique pelo fato de dificilmente deixarem sinais aparentes, evitando, assim, a comprovação da violência sexual e o recaimento de culpa sobre si. Quanto aos adolescentes, houve dois casos de atos libidinosos e três casos envolvendo penetração.

As formas de coerção ou intimidação utilizadas pelos agressores foram ameaça, força física, sedução e outras não identificadas. Observou-se que, em algumas situações, o agressor utilizou mais de uma forma de coerção. A ameaça foi a forma mais utilizada (41,93\%), seguida pelo uso de força física $(29,03 \%)$ e pela sedução (16,12\%), não se verificando casos de emprego de arma de qualquer natureza. As ameaças freqüentemente se referiam ao fato de 0 agressor dizer que relataria a violência para a genitora ou o responsável não agressor, de modo que a vítima temia ser culpada pela situação.

Ao se analisar a violência sexual de forma mais contextualizada, destaca-se a inadequação de isolá-la das intimidações constituídas como violência psicológica e violência física que, freqüentemente, a acompanham, e cujos efeitos, algumas vezes, se inscrevem como agravantes maiores que os da própria violência sexual. Familiares perpetradores ameaçam suas crianças com ferimentos, morte ou abandono, caso a violência seja revelada (Kaplan \& Sadock, 1990). As ameaças contribuem para a manutenção do segredo que, em muitos casos de violência intra-familiar, envolve todos os membros da família como cúmplices (Kristensen et al., 2001). A criança, além de não ser ainda capaz de compreender a gravidade e a amplitude da agressão de que é vítima, também não possui crítica desenvolvida para compreender o "jogo". Teme que o agressor relate a violência e que esta possa ser interpretada como uma atitude de indisciplina ou desobediência de sua parte, podendo, em decorrência disto, ser castigada ou perder 0 afeto de figuras parentais amadas.
Foi possível verificar seis modos pelos quais se deu a identificação da violência sexual: relato da vítima (36,36\%), presença de sinais físicos (18,18\%), faltas às aulas $(18,18 \%)$, alteração de comportamento $(13,63 \%)$, comportamento sexual inadequado $(9,09 \%)$, e resposta a um questionário (4,54\%). 0 relato verbal da violência foi o meio de identificação mais freqüente, o que discorda da colocação de Williams (2004), que sugere que, entre as vítimas de violência sexual, poucas relatariam a violência a outras pessoas e, dentre estas, uma parcela ainda menor relataria 0 fato às autoridades. Em um estudo realizado porKristensen et al.(2001),com meninos vítimas de violência sexual, para estes e seus familiares, revelar ou não a violência para outra pessoa esteve relacionado com a avaliação das conseqüências dessa revelação.

Lamentavelmente, mesmo com o relato das vítimas, muitos casos de violência são ignorados; 0 ouvinte não se importa, não se compromete ou não acredita naquilo que ouve, como foi um dos casos deste estudo, em que a vítima de 14 anos havia relatado, tanto para a professora, quanto para a orientadora de estudos bíblicos, que seu pai praticava atos libidinosos com ela, sendo que a genitora também sabia da violência. Brino e Williams (2001) afirmam que a violência sexual ainda é considerada um tabu por vários professores que, despreparados, fazem vista grossa, minimizam ou fazem comentários inadequados ou preconceituosos, expondo e levando a vítima a se sentir culpada.

Outro tipo de atitude adotada com alguma freqüência, após a revelação, pode ser exemplificado com o caso de uma garota de 12 anos, que relatou à professora que seu padrasto praticava atos libidinosos com ela. A professora convocou a mãe da criança e contou-Ihe o que acabara de saber. A criança não foi mais à escola, e a família mudou-se imediatamente para local ignorado. Segundo Drezett (2000), a genitora, na maioria dos casos, assume o papel de protetora do marido, de forma a negligenciar as necessidades emocionais da criança, mesmo tendo conhecimento da violência, como parece ter ocorrido nos dois casos relatados.

As faltas escolares aparecem em segundo lugar, juntamente com a presença de sinais físicos, como via de identificação da violência sexual. Fissuras, edemas, vermelhidão, queixas de dore ardência na região genital e/ou anal foram os sinais identificados pelas professoras durante o banho e apontados como sugestivos de 
violência sexual em quatro casos. Acredita-se que, justamente pelo fato de a violência sexual cometida por meio de atos físicos ser mais explícita, os agressores prefiram os atos libidinosos, que dificilmente deixam sinais aparentes. Em apenas $6 \%$ de 200 casos de atos libidinosos estudados por Kühn, Reis e Trindade Filho (1998), foram encontrados sinais de violência. No estudo a que se refere este artigo, nos casos em que a violência foi identificada pelas faltas, a direção escolar convocou a família e soube que as vítimas deixavam suas casas para irem à escola, mas, no caminho, eram interceptadas pelos agressores.

Alterações no comportamento das crianças conduziram à identificação em três casos. Foram duas as ocorrências em que a identificação baseou-se em comportamentossexualizados. Em um deles, um garoto de cinco anos tentou violentar o coleguinha e, ao ser questionado onde aprendera tais comportamentos, revelou à professora que seu pai fazia com ele os mesmos atos. Tratava-se de atos libidinosos, sem maiores especificações. No segundo caso, um garoto de 12 anos exibiu o pênis para um colega de sala, sendo suspenso das aulas depois do episódio. Após o término da suspensão, o garoto relatou para a diretora que havia sido violentado por um vigia de sua rua.

Brino e Williams (2003), investigando os sintomas característicos de vitimização sexual apontados por professoras, encontraram dados semelhantes aos descritos pela literatura (Kristensen et al., 2001; Williams, 2002), exceto "falar sobre o problema" que, neste trabalho, foi a principal via de identificação da violência sexual.Comportamentos sexualizados, mais apontados pela literatura como sintomáticos, foram utilizados como indicadores em apenas dois casos, reforçando a hipótese apontada por Brino e Williams (2003) de que as professoras detêm um conhecimento muito superficial sobre a violência sexual e sua sintomatologia.

Quanto ao local em que a violência ocorreu, os dados apontam, com maior freqüência, a residência do agressor (40,90\%); em seguida, a violência aparece na residência da vítima e do agressor (36,36\%), e na residência da vítima $(9,09 \%)$. Convém lembrar que a violência sexual doméstica e a intra-familiar são as mais comumente praticadas contra crianças. Na maioria dos casos, a violência perpetrada na residência do agressor, por tratar-se de pessoa conhecida e ter a confiança dos familiares da vítima, ocorre sem maiores transtornos ou suspeitas. Em seguida, há a ocorrência com maior freqüência da violência nos lares de ambos, vítima e agressor. Drezett (2000) constatou que os casos de violência sexual ocorridos em espaços públicos estão relacionados, principalmente, com os grupos femininos de adolescentes e adultas e que, no grupo de crianças, a maioria dos crimes sexuais é cometida em ambiente privado, especialmente nas residências. Esses resultados concordam com os deste estudo, que indicam a ocorrência da violência sexual, durante a infância, predominantemente nos lares do agressor, da vítima ou de ambos.

A professora (todas eram do sexo feminino) foi a profissional que mais identificou a violência sexual, seja pelas faltas, por relato direto da vítima, por alteração de comportamento ou pela presença de sinais físicos, em 16 casos (72,72\%). Coube a ela a decisão de convocar a família, ouvi-la e orientá-la, ou não. Os genitores de quatro dos casos, ao serem atendidos pelo Viver, disseram ter denunciado a violência porque a professora que a identificou assim os orientou. A diretora foi citada como responsável pela identificação de cinco casos de violência $(22,72 \%)$, sendo que,em dois deles, sua atuação foi decisiva para o encaminhamento. A intervenção de uma psicóloga foi citada em dois casos.

A infância e a adolescência são perío dos de vida em que essas populações têm um maior contato com os serviços públicos, principalmente a escola e os serviços de saúde. Essas instituições, além de suas finalidades específicas, podem atuar como serviços de proteção. Denominado de Rede de Proteção às Crianças e Adolescentes em Situação de Risco para Violência, esse sistema foi criado como um potencial de atuação para redução da vulnerabilidade destas populações à violência intra-familiar, construção de informações e indicadores e atendimentos a vítimas, familiares e agressores. Não se trata de um novo serviço, mas de uma nova concepção de trabalho que envolve, de forma integrada, instituições que desenvolvem suas atividades com crianças, adolescentes e seus familiares, especialmente escolas, creches, hospitais, programas de complementação de turno escolar, entre outros (Oliveira, Pfeiffer, Ribeiro, Gonçalves \& Ruy, 2004). A concepção de atendimento em rede parece ser uma das possíveis soluções para um enfrentamento mais eficaz da problemática da violência sexual, propondo que todos os casos identificados sejam acompanhados e monitorados pela rede local. 


\section{Considerações Finais}

Rompendo barreiras econômicas, sociais, religiosas e étnicas, o fenômeno da violência sexual constitui um grande desafio aos diversos setores e profissionais que se deparam com sua ocorrência. 0 presente estudo demonstrou, ainda que se suponha que essas estatísticas estejam muito aquém das verdadeiras incidências da violência sexual, o quão expostas estão crianças e adolescentes às diversas manifestações dessa modalidade de violência.

Dentre 2522 vítimas de violência sexual, a escola contribuiu para a identificação ou revelação da violência em apenas 0,91\% dos casos. Nos 22 casos estudados, houve o predomínio do sexo feminino, com $86,36 \%$, e da faixa etária "até 12 anos" (77,27\%). A principal figura do universo escolar a identificar a violência foi a professora, e a principal via de identificação utilizada foi o relato verbal da vítima. Os dados deste estudo demonstram que 0 agressor freqüentemente é alguém conhecido da vítima, e que as formas de intimidação mais utilizadas são a ameaça e a força física e, independente do local em que ocorram, as formas de violência mais praticadas são os atos libidinosos.

Nota-se que, em geral, a identificação baseou-se em evidências muito claras, o que leva à suposição de que os sinais mais sutis passam despercebidos pelos profissionais da escola. Os resultados deste estudo, juntamente com os dados da literatura, sugerem como fatores responsáveis pelos baixosíndices de identificação da violência sexual pela escola: o desconhecimento, por parte das educadoras, do ECA e das penalidades aplicáveis ao profissional que não denuncia a suspeita ou a ocorrência da violência; 0 desconhecimento das conseqüências da violência sexual sobre o desenvolvimento infanto-juvenil; e a necessidade de fatores altamente indicativos de violência sexual, tais como auto-relato e presença de sinais físicos. $\mathrm{Na}$ esfera da sexualidade, a atual postura social antagônica e contraditória, que ora estimula a erotização e ora a pune, constitui um dos muitos obstáculos existentes para a intervenção e prevenção na problemática da violência sexual. Por outro lado, a estrutura dos cursos de formação de educadores, de modo geral, não os capacita para a identificação e intervenção nos casos de violência sexual.

A revelação, a denúncia e a prevenção da

20 violência percorrem caminhos muitas vezes tortuosos.
Alguns profissionais suspeitam de ou identificam sua ocorrência, mas, lamentavelmente, optam pelo comodismo da dúvida e pelo silêncio, esquivando-se de suas responsabilidades e negligenciando os direitos do outro. É importante que o educador perceba que, em muitos momentos, na vida destas crianças e adolescentes, 0 professor pode ser a única figura capaz de protegê-las de alguma forma, mesmo que seja por meio de denúncia anônima.

Para que a escola possa garantir a qualidade de vida de sua clientela e promover a cidadania, deve conhecero universo de informações sobre o tema, sobre a legislação a respeito, sobre os direitos da criança e sobre o desenvolvimento infanto-juvenil, para delinear um programa que possa capacitar seus profissionais. Não se trata de delegar a responsabilidade pela transformação da sociedade à Educação, ou de acreditar que os problemas econômicos e sociais serão resolvidos porum ensino qualificado, mas trata-se do reconhecimento do papel fundamental da escola neste processo. Às vítimas de violência doméstica, a escola pode oferecer outros modelos de solução do problema e enfrentamento, promovendo grupos de discussão sobre - ECA, desmistificando crenças sobre práticas educativas prejudiciais, violentas e abusivas, e promovendo oportunidadesque desenvolvam o relacionamento com o grupo e com as diferenças.

\section{Referências}

Associação Brasileira Multiprofissional de Proteção à Infância e à Adolescência. (1997). Abuso sexual: mitos e realidade. Petrópolis: Autores \& Agentes Associados.

Amazarray, M. R., \& Koller, S. H. (1998). Crianças vítimas de abuso sexual: alguns aspectos observados em seu desenvolvimento. Psicologia, Reflexão e Crítica, 11 (3), 559-578.

Agência de Notícias dos Direitos da Infância. (2003). 0 grito dosinocentes: osmeios decomunicação ea violência sexual contra crianças eadolescentes. São Paulo: Cortez.

Araujo, M. F. (2002). Violência e abuso sexual em família. Psicologia em Estudo, 7 (2), 3-11.

Azevedo, M. A., \& Guerra, V. N. A. (1988).Peledeasno não ésó história: um estudo sobrea vitimização sexual de criançase adolescentes em família. São Paulo: Roca.

Beland, K. R. (1996). A schoolwide approach to violence prevention. In R. L. Hampton, P. Jenkins \& T. Gullotta. Issues in children's and families 'lives: preventing violence in America (pp.209-230). London: Sage publications.

Boney-Mccoy, S., \& Finkelhor, D. (1995). A risk factor for child sexual abuse and for PSTD-related symptomatology 
among sexually abused youth. Child Abuse \& Neglect, 19 (12), 1401-1421.

Brino, R. F., \& Williams, L. C. A. (2003). Concepções da professora acerca do abuso sexual infantil. Cadernos Pesquisa, 119, 113-128.

Conselho Estadual dosDireitos da Criança e do Adolescente. (1990). Estatuto da criança e do adolescente. São Paulo.

Dattilio, F. M., \& Freeman, A. (1995). Estratégias cognitivo comportamentais para intervenção em crises: tratamento deproblemasclínicos. São Paulo: Editoriais Psy II.

David. E. (1997). Violência e escola. Vertentes, 3, 1-153.

Drezett, J. (2000). Manejo integral da violência sexual pelos serviços públicos desaúde. Recuperado novembro, 2004 disponível em http:www.ipas.org.br/arquivos/jefferson /bolivia4.doc

Drezett, J. (2004). Estudo de fatores relacionados com a violência sexual contra crianças, adolescentes e mulheres adultas. Tese de doutorado não-publicada, Centro de Referência da Saúde da Mulher e de Nutrição, Alimentação e Desenvolvimento, São Paulo. Recuperado em setembro, 2004, disponível em http: www.rhamas.org. $\mathrm{br} /$ tesel

Faleiros, V. P. (1998). A violência sexual contra crianças e adolescentes e a construção de indicadores: a crítica do poder, da desigualdade e do imaginário. In M. F.P. Leal \&M. A. César (Orgs.),Indicadores deviolência intra-familiar e exploração sexual comercial de crianças e adolescentes (pp. 9-28). Brasília: CECRIA.

Faleiros, E. T. S., \& Campos, J. O. (2000). Repensando os conceitosdeviolência, abuso eexploração sexual decrianças e de adolescentes. Brasília: Unicef. Recuperado em setembro,2004, disponível em http: www.cecria.org.br/ banco/violencia.htm

Ferrari, D. C. A., \& Vecina, T. C. C. (2002). O fim do silêncio na violência familiar: teoria eprática. São Paulo: Ágora.

Finkelhor, D., \& Tackett, K. K. (1997). A developmental perspective on the childhood impact of crime, abuse, and violent victimization. In D. Cicchetti \& S. L. Toth Developmental perspectiveson trauma:theory, research, and intervention (pp.1-32). New York: University of Rochesler Press.

Gabel, M. (1997). Crianças vítimas deabuso sexual. São Paulo: Summus.

Gomes, R., J unqueira, M. F. P. S., Silva, C. O., \& Junger, W. L. (2002). A abordagem dos maus-tratos contra a criança e 0 adolescente em uma unidade pública de saúde. Ciência eSaúdeColetiva, 7 (2), 275-283.

Kaplan, H. I., \& Sadock, B. J. (1990). Compêndio depsiquiatria. Porto Alegre: Artes Médicas.

Knutson, J. F. (1995). Psychological characteristics of maltreated children: putative risk factors and consequences. Annual Review of Psychology, 46, 401-31.

Kristensen, C. H., Flores, R. Z., \& Gomes, W. B. (2001). Revelar ou não revelar: uma abordagem fenomenológica do abuso sexual com crianças. In M. A. T. Bruns \& A. Furtado (Orgs.), Psicologia e pesquisa fenomenológica: reflexões e perspectivas. São Paulo: Omega.
Kühn, M. L. S., Reis, J. E. S., \& Trindade Filho, A. (1998). Abuso sexual na infância. Trabalho apresentado no XVCongresso Brasileiro de Medicina Legal. Salvador-Bahia. Recuperado em novembro, 2004, disponível em http: www. geocities.com/projetopiracema / violencia.htm

Lisboa, C., Koller, S. H., Ribas, F. F., Bitencourt, K., Oliveira, L., Porciuncula, L. P.,\&De Marchi, R. B. (2002). Estratégias de coping de crianças vítimas e não vítimas de violência doméstica. Psicologia, Reflexão e Crítica, 15 (2), 345-362.

Minayo, M. C. S. (2002). 0 significado social e para a saúde da violência contra crianças e adolescentes. In $M$. F. Westphal. Violência ecriança. São Paulo: Edusp.

Ministério da Saúde. Brasil. (1998). Saúde da mulher prevenção e tratamento dos agravos resultantes da violência sexual contra mulheres e adolescentes. Brasília: Ministério da Saúde.

Ministério da Saúde.Brasil. (2002). Notificação demaus-tratos contra crianças e adolescentes pelos profissionais de saúde: um passo a maisna cidadania em saúde. Brasília:M inistério da Saúde.

Monteiro Silva,A. M.(1995). A violência na escola: a percepção dos alunos e professores. Sérieldéias, 28, São Paulo: FDE, 253-267. Acessado em outubro 2004, disponível em http: www.dhnet.org.br/educar/redeedh/bib/AIDA2. HTM

Neves, D. B. S., Ramirez, C. F. G., \& Brum, I. R. (2004). Atendimento a crianças e adolescentes vítimas de violência sexual: experiência em Manaus. In Brasil. Ministério da Saúde. Violência faz mal à saúde (pp.163-175). Brasília: Ministério da Saúde.

Oliveira, V. L. A., Pfeiffer, L., Ribeiro, C. R., Gonçalves, M. T., \& Ruy, I. A. E. (2004). Redes de proteção: novo paradigma de atuação: experiência de Curitiba. In Brasil. Ministério da Saúde. Violência faz malà saúde(pp. 143-161). Brasília: Ministério da Saúde.

Pereira da Silva, N. (2000). Violência doméstica: o quea escola tem a ver com isso? Recuperado em dezembro, 2004, disponível em http: www.pgj.ma.gov.br/caop_manu 2000 10.asp

Polanczyk, G. V., Zavaschi, M. L., Benetti, S., Zenker, R., \& Gammerman, P. W. (2003). Violência sexual e sua prevalência em adolescentes de Porto Alegre, Brasil. Revista deSaúde Pública, 37 (1), 8-14.

Ristum, M., \& Bastos, A. C. S. (2004). Violência urbana: uma análise dos conceitos de professores do ensino fundamental. Ciência e Saúde Coletiva, 9 (1), 225-239.

Williams, L. C. A. (2002). Abuso sexual infantil. In H. J. Guilhardi, M. B. B. Madi, P. P. Queiroz \& M. C. Scoz (Orgs.), Sobre comportamento e cognição: contribuições para a construção da teoria do comportamento. Santo André: ESETec. Recuperado em novembro, 2004, disponível em http: www.ufscar.br/ cech/laprev/abuso.pdf

Wolak, J.,\&Finkelhor, D. (1998). Children exposed to partner violence. In J.L. Jasink \& L. M. Willieams. Partnerviolence: a comprehensive review of 20 years of research (pp.73-112). Thousand Oaks: Sage Publications.

Recebido em: 14/2/2006

Versão final reapresentada em: 15/12/2006

Aprovado em:23/3/2007 